\title{
Diagnostic hysteroscopy in a procedure room setting compared to diagnostic hysteroscopy in the operating room
}

\author{
Ayman Oraif* \\ Department of Obstetrics and Gynecology, King Abdulaziz University, Jeddah, Saudi Arabia
}

Received: 17 September 2016

Accepted: 15 October 2016

\section{*Correspondence:}

Dr. Ayman Oraif,

E-mail: ayman_oraif@yahoo.com

Copyright: ( $)$ the author(s), publisher and licensee Medip Academy. This is an open-access article distributed under the terms of the Creative Commons Attribution Non-Commercial License, which permits unrestricted non-commercial use, distribution, and reproduction in any medium, provided the original work is properly cited.

\section{ABSTRACT}

Background: To examine patients' perceptions of and satisfaction with diagnostic hysteroscopy with endometrial biopsy in a procedure room/office setting as compared to diagnostic hysteroscopy with dilation and curettage (D\&C) performed in the operating room (O.R.).

Methods: This comparative quality improvement study contrasts diagnostic hysteroscopy with endometrial biopsy in a procedure room and diagnostic hysteroscopy with dilation and curettage in the operating room. 66 women participated in the study. Variables examined were: length of hospital stay, anesthesia and analgesia used, pain scores, recovery time, overall experience and satisfaction associated with the procedure.

Results: The O.R. group spent on average an additional 2 hours and 21 minutes in hospital compared to the procedure room group. The procedure room group received local blocks without the presence of an anaesthetist whereas the O.R. group received a range of intravenous (I.V.) medications given by an anaesthetist in addition to a local block. There was a slight increase in perceived pain among the procedure room group immediately following the procedure. However, no difference was observed between the pain scores collected upon discharge. More women from the O.R. group missed work due to their procedure compared to those in the procedure room group. Those from the procedure room group were able to return to their normal activities much sooner than those in the O.R. group and all of them indicated that they would prefer the same location in the future. A quarter of the patients in the O.R. group would prefer to have it performed in the procedure room, instead of the OR in the future

Conclusions: Diagnostic hysteroscopy is currently considered a valuable investigational tool for endometrial abnormalities and abnormal uterine bleeding. Most of these procedures can be performed in a procedure room setting without I.V. sedation or pre-operative narcotics. In our experience, a utero-sacral block using lidocaine is quite effective in controlling discomfort while passing various instruments through the internal cervical os. These techniques result in good visualization of the endometrial cavity, adequate and appropriate endometrial sampling with tolerable discomfort. The patients spend less time in the hospital, experience a much faster recovery and have less pre-operative restrictions.

Keywords: Diagnostic hysteroscopy, Endometrial biopsy, Operating room, Patient satisfaction, Procedure room, Recovery time, Utero-sacral block

\section{INTRODUCTION}

It is estimated that approximately $30 \%$ of all visits to gynaecologists are linked to symptoms of abnormal uterine bleeding (AUB). AUB is the second most common gynaecological complain and has traditionally been investigated by dilation and curettage $(\mathrm{D}$ and $\mathrm{C}){ }^{1-3}$ The sensitivity of a D and $\mathrm{C}$ when performed alone is only $65 \%$ compared to $98 \%$ when combined with hysteroscopy. ${ }^{4-6}$ Due to availability of other less invasive 
and more sensitive and specific modalities, D and C is used less frequently. These include the use of hysterosalpingogram, vaginal ultrasound, hysterosonogram and diagnostic hysteroscopy. Raziel et al. demonstrated a sensitivity of $74 \%$ and specificity of $60 \%$ for hysterosalpingography, whereas Vercellini et al. showed the vaginal ultrasound values to be 85 and $84 \% .^{7,8}$

Hysterosonogram revealed a sensitivity of $88.8 \%$ and a specificity of $84.4 \%$ in a study done by Gumus et al. ${ }^{9}$ Fedele et al. reported the sensitivity of hysteroscopy to be $100 \%$ and the specificity to be $95 \%$. ${ }^{10}$ Pelvic ultrasound and endometrial biopsy are the traditional initial investigations for abnormal uterine bleeding. However, the low specificity and sensitivity in diagnosing intra uterine disease may delay the ultimate diagnosis and appropriate management. Diagnostic hysteroscopy with endometrial sampling enables the clinician to make the correct diagnosis and initiate appropriate therapy rather than waiting for possible resolution of the problem or resorting to more aggressive therapy such as hysterectomy. New technologies with smaller instrumentation are as well tolerated as office endometrial biopsy with no significant increase in morbidity and a more accurate diagnosis. ${ }^{11,12}$

Diagnostic hysteroscopy may be used as the first line of investigation for various gynaecological complaints including AUB, postmenopausal bleeding and amenorrhea. ${ }^{1}$

Whereas endoscopy is accepted to be performed in a procedure room in gastrointestinal medicine, the same is not true of diagnostic hysteroscopy in the gynaecology field. It has been estimated that only $15 \%$ of gynaecologists in the United States routinely perform procedure room hysteroscopy, with only a little over a third of the membership of the American Association of Gynecological Laparoscopists even occasionally performing procedure room hysteroscopy. ${ }^{1,13}$

The purpose of this study was to examine patients' perceptions of and satisfaction with diagnostic hysteroscopy with endometrial biopsy in procedure room without the presence of an anaesthetist as compared with diagnostic hysteroscopy and D and $\mathrm{C}$ performed in the O.R. for AUB.

\section{METHODS}

Patients were given a self-administered questionnaire to complete during recovery and participated in a telephone interview between one and three days following their procedure. Additional information, such as admission time, discharge time, age, diagnosis and medications administered was collected from the patients' health records. .
SPSS for analysis was utilized. Ethics approval was obtained. Participants were recruited by means of convenience sampling. Every woman with a diagnosis related to abnormal bleeding and scheduled for hysteroscopy in the procedure room or a hysteroscopy and $\mathrm{D}$ and $\mathrm{C}$ in the operating room between June and August 2008, were asked to participate. Those patients undergoing additional procedures such as thermal endometrial ablation; polypectomy; laparoscopic tubal ligation; diagnostic laparoscopy; replacement, removal, or insertion of an intra-uterine device (IUD); and tension free vaginal tape obturator (TVTO) were excluded. None of the subjects approached declined to participate. Subject recruitment took place over a period of 10 weeks.

All surgeons in both groups were experienced gynaecologists. Visualization of the endometrial cavity was satisfactory in all cases and endometrial sampling yielded appropriate histological samples.

\section{Procedure room diagnostic hysteroscopy}

Patients undergoing diagnostic hysteroscopy and biopsy in the procedure room arrived approximately half an hour before their scheduled procedure. Patients were asked to consume clear fluids only for four hours pre-op. The procedure itself began with a pelvic examination to assess uterine size and for adnexal masses. Approximately 2-3 cc of lidocaine was injected into the anterior lip of the cervix prior to grasping it with a single toothed tenaculum. Then, $10 \mathrm{cc}$ of lidocaine was injected into the utero-sacral ligaments on each side. This was done at 5 and 7 clock and a total of $20 \mathrm{cc}$ was used, in order to alleviate discomfort during the procedure. Hysteroscopy was performed with a $2.3 \mathrm{~mm}$ rigid hysteroscope with a $3.5 \mathrm{~mm}$ outer sheath. No forceful dilation with dilators was used and dilation of the internal os was accomplished by hydro distension under direct vision. A continuous flow of distension fluid (normal saline) allowed a good view of the endometrial cavity and tubal ostia. Hysteroscopic images were displayed on a high definition monitor for both the patient and physician to view. Endometrial biopsy was then performed. Results of the hysteroscopy were communicated orally to the patient immediately following the procedure once they were stable.

\section{Operating room hysteroscopy}

Patients undergoing diagnostic hysteroscopy with D and $\mathrm{C}$ in the O.R. were admitted to the surgical centre approximately 2 hours before their scheduled procedure. Patients were required to fast during the 12 hours preceding hysteroscopy. All Patients were given intravenous sedation (Figure 1) and a paracervical block using lidocaine. Hysteroscopy was performed with a 5 $\mathrm{mm}$ outer sheath rigid hysteroscope, preceded by dilation of the cervix using dilators. Curettage was then performed with a sharp curette. 


\section{RESULTS}

A total of 66 women participated in the data collection for this project, with an equal number (33) in each group (Table 1). Those from the O.R. group spent on average an additional 2 hours and 21 minutes in hospital than those from the procedure room group.

Table 1: Characteristics of patients from the procedure room compared to the O.R.

\begin{tabular}{|c|c|c|c|}
\hline $\begin{array}{l}\text { Patient } \\
\text { Characteristic }\end{array}$ & $\begin{array}{l}\text { O.R. } \\
(n=33)\end{array}$ & $\begin{array}{l}\text { Procedure } \\
\text { room } \\
(n=33)\end{array}$ & $\begin{array}{l}\text { Total } \\
(\mathbf{N}=66)\end{array}$ \\
\hline Mean age (range) & $\begin{array}{l}50.5 \\
(39- \\
66)\end{array}$ & $\begin{array}{l}46.1 \\
(29-69)\end{array}$ & $\begin{array}{l}48.2 \\
(29-69)\end{array}$ \\
\hline $\begin{array}{l}\mathrm{ALOS}^{*} \text { hrs: min } \\
\text { (range) }\end{array}$ & $\begin{array}{l}4: 06 \\
(1: 50- \\
7: 22)\end{array}$ & $\begin{array}{l}1: 45 \\
(1: 05-2: 22)\end{array}$ & $\begin{array}{l}2: 48 \\
(1: 05- \\
7: 22)\end{array}$ \\
\hline \multicolumn{4}{|l|}{ Primary diagnosis } \\
\hline Menorrhagia & 9 & 16 & 25 \\
\hline $\begin{array}{l}\text { Post-menopausal } \\
\text { bleeding }\end{array}$ & 12 & 3 & 15 \\
\hline $\begin{array}{l}\text { Abnormal uterine } \\
\text { bleeding }\end{array}$ & - & 6 & 6 \\
\hline $\begin{array}{l}\text { Dysfunctional uterine } \\
\text { bleeding }\end{array}$ & 5 & - & 5 \\
\hline $\begin{array}{l}\text { Thickened } \\
\text { endometrium }\end{array}$ & 2 & 1 & 3 \\
\hline Endometrial polyp & 2 & - & 2 \\
\hline Menometrorrhagia & 2 & - & 2 \\
\hline Other & - & 2 & 2 \\
\hline
\end{tabular}

Table 2: Average level of pain post-procedurally and at discharge for women undergoing diagnostic hysteroscopy performed in the O.R. and the procedure room.

\begin{tabular}{|llll|}
\hline $\begin{array}{l}\text { Hysteroscopy } \\
\text { location }\end{array}$ & $\begin{array}{l}\text { A verage level of pain (VAS cm) } \\
\text { Post- } \\
\text { procedural } \\
\text { (range) }\end{array}$ & $\begin{array}{l}\text { Discharge } \\
\text { (range) }\end{array}$ & $\begin{array}{l}\text { Post- } \\
\text { procedural } \\
- \\
\text { discharge }\end{array}$ \\
\hline OR $(\mathrm{n}=29)$ & $\begin{array}{l}0.86(0- \\
2.3)\end{array}$ & $\begin{array}{l}0.47(0- \\
2.0)\end{array}$ & 0.41 \\
\hline $\begin{array}{l}\text { Procedure } \\
\text { room }(\mathrm{n}=33)\end{array}$ & $\begin{array}{l}2.44(0- \\
8.5)\end{array}$ & $\begin{array}{l}1.12(0- \\
6.7)\end{array}$ & 1.11 \\
\hline P value & 0.002 & 0.028 & - \\
\hline
\end{tabular}

Those who underwent hysteroscopy in the procedure room received only a local anaesthetic (utero-sacral block) whereas those who underwent operative hysteroscopy in the O.R. received a range of medications (Figure 1). All women from the O.R. group received one or more I.V. sedatives, a local anaesthetic (lidocaine) and at least one analgesic medication. Most women (93.9\%) also received an antiemetic such as dimenhydrinate (Gravol). Some women also received an anti- inflammatory $(39.4 \%)$, antacid $(36.4 \%)$, or respiratory medication $(24.2 \%)$.

Table 3: Side effects of women undergoing diagnostic hysteroscopy in the O.R. and the procedure room.

\begin{tabular}{|lll|}
\hline Patient response & $\begin{array}{l}\text { O.R. } \\
(\mathrm{n}=29)\end{array}$ & $\begin{array}{l}\text { Procedure } \\
\text { room } \\
(\mathrm{n}=33)\end{array}$ \\
\hline Experiencing nausea & \\
\hline No & $27(93 \%)$ & $28(85 \%)$ \\
\hline Mild nausea & $2(7 \%)$ & $3(9 \%)$ \\
\hline Moderate nausea & - & $2(6 \%)$ \\
\hline Severe nausea & - & - \\
\hline Vomiting & - & - \\
\hline Feeling faint or dizzy & $24(83 \%)$ & $9(27 \%)$ \\
\hline No & $3(10 \%)$ & $20(61 \%)$ \\
\hline Mild dizziness & - & $2(6 \%)$ \\
\hline Moderate dizziness & - & $1(3 \%)$ \\
\hline Severe dizziness & - & $1(3 \%)$ \\
\hline No response & $2(7 \%)$ & $25(76 \%)$ \\
\hline Feeling drowsy & $12(41 \%)$ & $6(18 \%)$ \\
\hline \begin{tabular}{l} 
No \\
\hline $\begin{array}{l}\text { Minimally } \\
\text { difficult }\end{array}$
\end{tabular} & $11(38 \%)$ \\
\hline $\begin{array}{l}\text { Somewhat } \\
\text { difficult }\end{array}$ & $6(21 \%)$ & $2(6 \%)$ \\
\hline Very difficult & \\
\hline${ }^{a}$ Difficulty staying awake & - & - \\
\hline
\end{tabular}

Table 4: Patient reported pain and discomfort from diagnostic hysteroscopy performed in the O.R. and procedure room.

\begin{tabular}{|c|c|c|c|}
\hline $\begin{array}{l}\text { Patient } \\
\text { Response }\end{array}$ & $\begin{array}{l}\text { O.R. } \\
(\mathbf{n}=32)\end{array}$ & $\begin{array}{l}\text { Procedure } \\
\text { room } \\
(\mathrm{n}=28)\end{array}$ & $\begin{array}{l}\text { Total } \\
(\mathrm{N}= \\
60)\end{array}$ \\
\hline \multicolumn{4}{|c|}{ During procedure $^{\mathrm{a}}$} \\
\hline No pain & $\begin{array}{l}26 \\
(81 \%)\end{array}$ & $1(4 \%)$ & $\begin{array}{l}27 \\
(45 \%)\end{array}$ \\
\hline Very little pain & $4(13 \%)$ & $6(21 \%)$ & $\begin{array}{l}10 \\
(17 \%)\end{array}$ \\
\hline Some pain & $2(6 \%)$ & $19(68 \%)$ & $\begin{array}{l}21 \\
(35 \%)\end{array}$ \\
\hline Very bad pain & - & $2(7 \%)$ & $2(3 \%)$ \\
\hline \multicolumn{4}{|c|}{ After procedure $(1-3 \text { days })^{b}$} \\
\hline No discomfort & $\begin{array}{l}18 \\
(56 \%)\end{array}$ & $17(61 \%)$ & $\begin{array}{l}35 \\
(58 \%)\end{array}$ \\
\hline Cramping & $8(25 \%)$ & $5(18 \%)$ & $\begin{array}{l}13 \\
(22 \%)\end{array}$ \\
\hline $\begin{array}{l}\text { General } \\
\text { discomfort }\end{array}$ & $6(19 \%)$ & $5(18 \%)$ & $\begin{array}{l}11 \\
(18 \%)\end{array}$ \\
\hline $\begin{array}{l}\text { Unspecified } \\
\text { discomfort }\end{array}$ & - & $1(4 \%)$ & $1(2 \%)$ \\
\hline
\end{tabular}

${ }^{a}$ As recalled during telephone interview, one to three days following procedure; ${ }^{b}$ Discomfort reported at time of telephone interview. 
Table 5: Patient satisfaction with diagnostic hysteroscopy performed in the O.R. and Procedure room: expectations, preference to repeat procedure, likelihood of recommending to others.

\begin{tabular}{|c|c|c|c|}
\hline Patient response & $\begin{array}{l}\text { O.R. } \\
(n= \\
32)\end{array}$ & $\begin{array}{l}\text { Procedure } \\
\text { room } \\
(\mathbf{n}=28)\end{array}$ & $\begin{array}{l}\text { Total } \\
(\mathbf{N}= \\
60)\end{array}$ \\
\hline \multicolumn{4}{|c|}{ Comparison to expectations } \\
\hline $\begin{array}{l}\text { Worse than } \\
\text { expected }\end{array}$ & $1(3 \%)$ & $7(25 \%)$ & $\begin{array}{l}8 \\
(13 \%)\end{array}$ \\
\hline As expected & $\begin{array}{l}10 \\
(31 \%)\end{array}$ & $10(36 \%)$ & $\begin{array}{l}20 \\
(33 \%)\end{array}$ \\
\hline $\begin{array}{l}\text { Better than } \\
\text { expected }\end{array}$ & $\begin{array}{l}21 \\
(66 \%)\end{array}$ & $11(39 \%)$ & $\begin{array}{l}32 \\
(53 \%)\end{array}$ \\
\hline \multicolumn{4}{|c|}{ Repeat procedure in future } \\
\hline Same way & $\begin{array}{l}28 \\
(88 \%)\end{array}$ & $28(89 \%)$ & $\begin{array}{l}56 \\
(93 \%)\end{array}$ \\
\hline $\begin{array}{l}\text { Without } \\
\text { sedation }^{\text {a }}\end{array}$ & $3(9 \%)$ & - & $3(5 \%)$ \\
\hline With sedation $^{\mathrm{b}}$ & - & - & - \\
\hline N/A & $1(3 \%)$ & - & $1(2 \%)$ \\
\hline \multicolumn{4}{|c|}{ Likelihood of recommending to others } \\
\hline Not at all likely & $1(3 \%)$ & - & $1(2 \%)$ \\
\hline Not likely & $1(3 \%)$ & - & $1(2 \%)$ \\
\hline Somewhat likely & $\begin{array}{l}9 \\
(28 \%)\end{array}$ & $10(36 \%)$ & $\begin{array}{l}19 \\
(32 \%)\end{array}$ \\
\hline Very likely & $\begin{array}{l}21 \\
(66 \%)\end{array}$ & $18(64 \%)$ & $\begin{array}{l}39 \\
(65 \%)\end{array}$ \\
\hline
\end{tabular}

${ }^{\mathrm{a}}$ Fully awake; ${ }^{\mathrm{b}} \mathrm{Put}$ to sleep

The patient was in the procedure room for approximately $10-15$ min and subsequently in the recovery room for an additional $15 \mathrm{~min}$. They were able to drive home. In the O.R. group, following their procedure, patients were taken to the Post Anesthesia Care Unit (PACU) for an approximately 45-minute recovery period. Many patients received various postoperative medications (Figure 1). Recovery then continued for 30 to 60 minutes where patients were monitored until able to be taken home. Patients were not allowed to drive themselves home after this procedure. Women from the procedure room group reported experiencing significantly more pain postprocedure $(p<0.01)$, with a mean pain score of 2.44 out of $10 \mathrm{~cm}$ on the VAS, compared with $0.86 \mathrm{~cm}$ for those from the O.R. group (Table 2). Although higher, the mean pain score of $2.44 \mathrm{~cm}$ is still considered mild or a low level of pain as it falls on the low end of the $10-\mathrm{cm}$ scale. Those from the procedure room gave a mean pain score of $1.12 \mathrm{~cm}$, still significantly higher than those from the O.R. $(\mathrm{p}<0.05)$ who gave a mean rating of 0.47 $\mathrm{cm}$.

For those who underwent diagnostic hysteroscopy in the procedure room, post-procedural pain scores were higher on average when biopsy was required. Women who required a biopsy of any abnormalities found during hysteroscopy $(n=19)$ gave a mean post-procedural pain score of 3.14 whereas those who did not require biopsy (n $=14)$ gave a mean pain score of $1.96(\mathrm{p}=0.066)$. No difference was observed between the pain scores collected upon discharge.

Table 6: Patient recovery after diagnostic hysteroscopy performed in the O.R. and procedure room.

\begin{tabular}{|c|c|c|c|}
\hline Patient Response & $\begin{array}{l}\text { O.R. } \\
(\mathbf{n}= \\
32)\end{array}$ & $\begin{array}{l}\text { Procedure } \\
\text { room } \\
(n=28)\end{array}$ & $\begin{array}{l}\text { Total } \\
(\mathbf{N}= \\
60)\end{array}$ \\
\hline \multicolumn{4}{|c|}{ Work missed due to procedure } \\
\hline Did not miss work & $12(38 \%)$ & $13(46 \%)$ & $25(42 \%)$ \\
\hline Missed work & $20(62 \%)$ & $14(50 \%)$ & $34(57 \%)$ \\
\hline $\begin{array}{l}\text { Mean hrs (days) } \\
\text { missed }\end{array}$ & $58.2(2.4)$ & $16.9(0.7)$ & - \\
\hline N/A & - & $1(4 \%)$ & $1(2 \%)$ \\
\hline \multicolumn{4}{|c|}{ Able to return to regular activities } \\
\hline No & $13(41 \%)$ & $1(4 \%)$ & $14(23 \%)$ \\
\hline Yes & $19(59 \%)$ & $27(96 \%)$ & $46(77 \%)$ \\
\hline Mean hrs (days) ${ }^{\mathrm{a}}$ & $31.3(1.3)$ & $6.9(0.3)$ & $19.1(0.8)$ \\
\hline \multicolumn{4}{|c|}{ Able to drive after procedure } \\
\hline Haven't driven & $11(34 \%)$ & $5(18 \%)$ & $16(27 \%)$ \\
\hline $\begin{array}{l}\text { Immediately } \\
\text { after }\end{array}$ & - & $17(61 \%)$ & $17(28 \%)$ \\
\hline $24 \mathrm{hrs}$ after & $10(31 \%)$ & $3(11 \%)$ & $1322 \%)$ \\
\hline $48 \mathrm{hrs}$ after & $2(6 \%)$ & - & $2(3 \%)$ \\
\hline 72 hrs after & - & - & - \\
\hline N/A & $9(28 \%)$ & $3(11 \%)$ & $12(20 \%)$ \\
\hline
\end{tabular}

${ }^{\mathrm{a}}$ Mean number of hours before able to return to regular activities

Most women did not report experiencing any significant side-effects as a result of their procedure (Table 3). 2 women $(7 \%)$ from the O.R. group and $5(15 \%)$ from the procedure room group reported experiencing any nausea. 3 women (10\%) from the OR group reported feeling mildly faint or dizzy and $17(59 \%)$ reported feeling drowsy after DandC and hysteroscopy. In contrast, 8 (24\%) women from the procedure room group reported feeling drowsy after their procedure and $23(70 \%)$ reported feeling faint or dizzy. Of the latter group of women, $87.0 \%$ (20/23) reported experiencing only mild faintness or dizziness after their hysteroscopic procedure.

Table 7: Patient preference for hysteroscopy performed in the O.R. or the procedure room.

\begin{tabular}{|llll|}
\hline $\begin{array}{l}\text { Patient } \\
\text { Preference }\end{array}$ & $\begin{array}{l}\text { O.R. } \\
(\mathbf{n}=32)\end{array}$ & $\begin{array}{l}\text { Procedure } \\
\text { room } \\
(\mathbf{n}=28)\end{array}$ & $\begin{array}{l}\text { Total } \\
(\mathbf{N}= \\
60)\end{array}$ \\
\hline $\begin{array}{l}\text { Operating } \\
\text { room }\end{array}$ & $21(66 \%)$ & - & $\begin{array}{l}21 \\
(35 \%)\end{array}$ \\
\hline $\begin{array}{l}\text { Procedure } \\
\text { room }\end{array}$ & $8(25 \%)$ & $28(100 \%)$ & $\begin{array}{l}36 \\
(60 \%)\end{array}$ \\
\hline N/A & $3(9 \%)$ & - & $3(5 \%)$ \\
\hline
\end{tabular}


A total of 32 and 28 telephone interviews were conducted with women from the O.R. group and the procedure room group respectively. Women were asked questions regarding aspects of their experience of hysteroscopy such as overall satisfaction, anxiety, pre-procedure preparations and recovery. Responses given during the interviews with respect to anxiety indicated that there were no marked differences between the groups.

While the majority of women from the O.R. group (81\%) reported feeling no pain, the majority of women from the procedure room group $(96 \%)$ reported feeling some degree of pain (Table 4). Women were also asked to report on whether they were experiencing any pain/discomfort at the time of interview. The O.R. group (44\%) overall had slightly more discomfort within a few days of their procedure than did those in the procedure room group (39\%). Patients characterized current symptoms as cramping in the lower abdomen or general discomfort.

Patients were also asked questions relating to their overall experience with hysteroscopy. Overall, the majority of women $(53 \%)$ felt that the procedure was better than what they had expected (Table 5): 10 women from each group felt that the procedure was just as they expected it to be; 1 woman from the O.R. group and 7 from the procedure room group felt that it was worse than expected. When asked if they were to have a repeat hysteroscopy procedure, the majority of women reported that they would have it performed in the same way $(93 \%)$.

In addition, patients were asked questions regarding their recovery after they had returned home. More women from the O.R. group $(62 \%)$ missed work due to their procedure compared to those in the procedure room group (50\%), missing an average of 2.4 days and 0.7 days of work respectively (Table 6). At the time of interview, 13 women from the O.R. group (41\%) reported that they had not yet returned to their regular activities while all but 1 from the procedure room had (Table 6). Those from the O.R. group were able to return to their normal activities an average of 1.3 days after hysteroscopy and those from the procedure room group were able to resume normal activities an average of 6.9 hours after their procedure. At the time of interview, many women from the O.R. group (34\%) still did not feel they were able to drive, while others required a day $(31 \%)$ or $2(6 \%)$ to recover before driving. In comparison, the majority of women from the procedure room group (61\%) were able to drive immediately after their procedure and none required more than 1 day of recovery before driving.

All those who underwent diagnostic hysteroscopy in the procedure room indicated that they would prefer the same location in the future (Table 7). However, a quarter of those who underwent hysteroscopy in the O.R. would prefer to have the procedure performed in the procedure room without conscious sedation.

\section{DISCUSSION}

Although colonoscopy has been accepted and performed in a procedure room in gastrointestinal medicine, diagnostic hysteroscopy is not commonly performed outside of the operating theatre. ${ }^{14}$

In this project, patients who have undergone diagnostic hysteroscopy with endometrial biopsy in the procedure room have reported higher severity of pain than those who have undergone diagnostic hysteroscopy with $\mathrm{D}$ and $\mathrm{C}$ in the O.R. However, the mean pain score of $2.44 \mathrm{~cm}$ for those from the procedure room is quite low on a 10$\mathrm{cm}$ VAS, and not different from levels of pain many people experience day to day. Similar values of pain intensity have been reported during procedure room hysteroscopy. ${ }^{14}$ Results of the telephone questionnaire confirm that pain that was experienced in the procedure room was not lasting or intense enough to trigger a sense of pain during recall questioning as almost all patients from the procedure room group (89\%) recalled experiencing only 'very little' or 'some' pain during the procedure. This concurs with results of a similar study, where $78 \%$ of patients considered the pain from procedure room hysteroscopy to be less than that usually experienced during menstruation. ${ }^{15}$

The difference in pain scores observed is not unexpected considering the medications that were administered within each group. Patients in the O.R., due to the use of pain alleviating drugs and conscious sedation, were not able to register or recall the pain. Analgesics were administered to every patient in the O.R. group, with $97.0 \%$ receiving more than two kinds of pain-killers of which at least one was a narcotic (morphine/hydromorphone) in addition to an amnesic (midazolam). Although both groups of women received a local anaesthetic before the procedure, those from the procedure room group were not sedated during the cervical injection as were those from the O.R. group. This seems to have contributed to the higher pain scores of women from the procedure room group. During the telephone questionnaire, several women reported that the injection of the local anaesthetic in the cervix was the worst part of their procedure. A similar finding has been reported by Nagele et al. who discontinued the use of a local anaesthetic routinely during procedure room hysteroscopy as many patients found the injection of anaesthetic as painful as the hysteroscopy itself. ${ }^{2}$

In addition to the administration of local anaesthetic, the need for endometrial biopsy may have also contributed to the higher pain scores. The difference in mean pain scores between women who did and did not require biopsy trended towards statistical significance $(\mathrm{p}=$ 0.066 ), with a difference of $1.18 \mathrm{~cm}$ on a $10-\mathrm{cm}$ VAS.

It has been found that age and post-menopausal status are associated with the incidence of intrauterine pathology and pain during hysteroscopy respectively. ${ }^{16,17}$ Schettini 
D et al. have also found that menopause alterations in the female genitalia usually require the need for additional cervical dilation and tenaculum use, which is another factor associated with pain, especially in patients not having experienced previous vaginal delivery. ${ }^{18}$

The patients' experience of hysteroscopy is also influenced by their recovery from the procedure. As those from the procedure room group did not need to recover from conscious sedation, they were able to return to work, to return to regular activities and to drive much sooner. These results are comparable those of Kremer et al. who compared procedure room and O.R. hysteroscopy in a randomized controlled trial; The procedure room group reached pre-operative fitness more quickly than the O.R. group ( 2 days vs. 3 days; $p<0.05$ ) and were fully mobile more quickly ( 0 min vs. $105 \mathrm{~min}$; $\mathrm{p}<0.001){ }^{15}$

The overall experience for patients from both groups was favourable and most patients found their respective procedures to be better than they had expected. Although higher values for pain during procedure room hysteroscopy have been reported, it has been concluded that procedure room hysteroscopy is still well tolerated (19). Although women report pain, Clark et al. (20) and De Iaco et al. have found that $84 \%$ and $83 \%$ of women respectively have found the procedure to be acceptable. ${ }^{21}$ Kremer et al. (15) similarly found that patients' satisfaction with hysteroscopy in a procedure room to be $83.6 \%$, compared with $77.0 \%$ for O.R. hysteroscopy.

\section{CONCLUSION}

Diagnostic hysteroscopy is currently considered one of the main investigation tools for endometrial abnormalities and abnormal uterine bleeding. Most of these procedures can be performed in a procedure room setting without I.V. Sedation, pre-operative narcotics or cervical preparation. In our experience, a utero-sacral block using lidocaine is quite effective in controlling discomfort while passing various instruments through the internal cervical os. These techniques result in good visualization of the endometrial cavity, adequate and appropriate endometrial sampling with tolerable discomfort. The patients spend less time in the hospital, experience a much faster recovery and have less pre-operative restrictions.

\section{ACKNOWLEDGMENT}

I would like to thank Dr Richard Boroditsky, Director of the mature women Centre for his time and effort in helping me with this paper.

Funding: No funding sources Conflict of interest: None declared

Ethical approval: The study was approved by the Institutional Ethics Committee

\section{REFERENCES}

1. Isaacson K. Office hysteroscopy: A valuable but under-utilized technique. Current Opinion in Obstetrics and Gynecology. 2002;14(4):381-5.

2. Nagele F, O'Connor H, Davies A. 2500 outpatient diagnostic hysteroscopies. Obstetrics and Gynecology. 1996;88(1):87-92.

3. Seamark CJ. The demise of the D and C. Journal of the Royal Society of Medicine. 1998;91(2):76-9.

4. Loffer FD. Hysteroscopy with selective endometrial sampling compared with $\mathrm{D}$ and $\mathrm{C}$ for abnormal uterine bleeding: The value of a negative hysteroscopic view. Obstetrics and Gynecology. 1989;73(1):16-20.

5. Readman E, Maher PJ. Pain relief and outpatient hysteroscopy: A literature review. Journal of the American Association of Gynecologic Laparoscopists. 2004;11(3):315-9.

6. Spicer JM, Siebert I, Kruger TF. Postmenopausal bleeding: A diagnostic approach for both private and public sectors. Gynecologic and Obstetric Investigation. 2006;61(3):174-8.

7. Raziel A, Arieli S, Bukovsky I, Caspi E, Golan A. Investigation of the uterine cavity in recurrent aborters. Fertil Steril. 1994;62(5):1080-2.

8. Vercellini P, Cortesi I, Oldani S, Moschetta M, De Giorgi O, Crosignani PG. The role of transvaginal ultrasonography and outpatient diagnostic hysteroscopy in the evaluation of patients with menorrhagia.Hum Reprod. 1997;12(8):1768-71.

9. Gumus II, Keskin EA, Kiliç E, Aker A, Kafali H, Turhan. Diagnostic value of hysteroscopy and hysterosonography in endometrial abnormalities in asymptomatic postmenopausal women. Arch Gynecol Obstet. 2008;278(3):241-4.

10. Fedele L, Bianchi S, Dorta M, Brioschi D, Zanotti F, Vercellini P. Transvaginal ultrasonography versus hysteroscopy in the diagnosis of uterine submucous myomas. Obstet Gynecol. 1991;77(5):745-8.

11. Kremer C, Barik S, Duffy S. Flexible outpatient hysteroscopy without anaesthesia: A safe, successful and well tolerated procedure. British Journal of Obstetrics and Gynaecology. 1998;105(6):672-6.

12. Rullo S, Sorrenti G, Marziali M, Ermini B, Sesti F, Piccione J. Office hysteroscopy: comparison of 2.7and 4-mm hysteroscopes for acceptability, feasibility and diagnostic accuracy. Reprod Med. 2005;50(1):45-8

13. Hulka JF, Levy DS, Luciano AA. 1997 AAGL membership survey: practice profiles. Journal of the American Association of Gyneologic Laparoscopists. 1998;5(2):93-6.

14. Campo R, Molinas CR, Rombauts L. Prospective multicentre randomized controlled trial to evaluate factors influencing the success rate of office diagnostic hysteroscopy. Human Reproduction. 2005;20(1):258-63.

15. Kremer C, Duffy S. Patient satisfaction with outpatient hysteroscopy versus day case 
hysteroscopy: Randomised controlled trial. BMJ. 2000;320(7230):279-82.

16. Al-Kamil RK. Clinical effectiveness of hysteroscopy in abnormal uterine bleeding. Journal of Obstetrics and Gynaecology. 2001;21(6):614-6.

17. Goldrath MH, Sherman AI. Office hysteroscopy and suction curettage: can we eliminate the hospital diagnostic dilation and curettage? American Journal of Obstetrics and Gynecology. 1985;152(2):220-9.

18. de Carvalho Schettini JA, Ramos de Amorim MM. Pain evaluation in outpatients undergoing diagnostic anesthesia-free hysteroscopy in a teaching hospital: A cohort study. Journal of Minimally Invasive Gynecology. 2007;14(6):729-35.

19. Yang J, Vollenhoven B. Pain control in outpatient hysteroscopy. Obstetrical and Gynecological Survey. 2002;57(10):693-702.
20. Clark S, Vonau B, Macdonald R. Topical anaesthesia in outpatient hysteroscopy. Gynaecological Endoscopy. 1996;5;141-4.

21. De Iaco P, Marabini A, Stefanetti M. Acceptability and pain of outpatient hysteroscopy. Journal of the American Association of Gynecologic Laparoscopists. 2010;7(1):71-5.

Cite this article as: Oraif $\mathrm{A}$. Diagnostic hysteroscopy in a procedure room setting compared to diagnostic hysteroscopy in the operating room. Int J Reprod Contracept Obstet Gynecol 2016;5:416473. 


\section{Appendix A}

Pain/Adverse event data collection form

Hysteroscopic Surgery in a Procedure Room Compared to the Operating Room

$\checkmark$ Mature Women's Centre

$\checkmark \quad$ SurgiCentre

Name: Date: $(\mathrm{mm} / \mathrm{dd} / \mathrm{yy})$

To be completed immediately POST-OP Time of Admission:

Visual Analog Scale (VAS):

Please rate the pain you are experiencing now by marking a line on the following scale from no pain to worst imaginable pain:

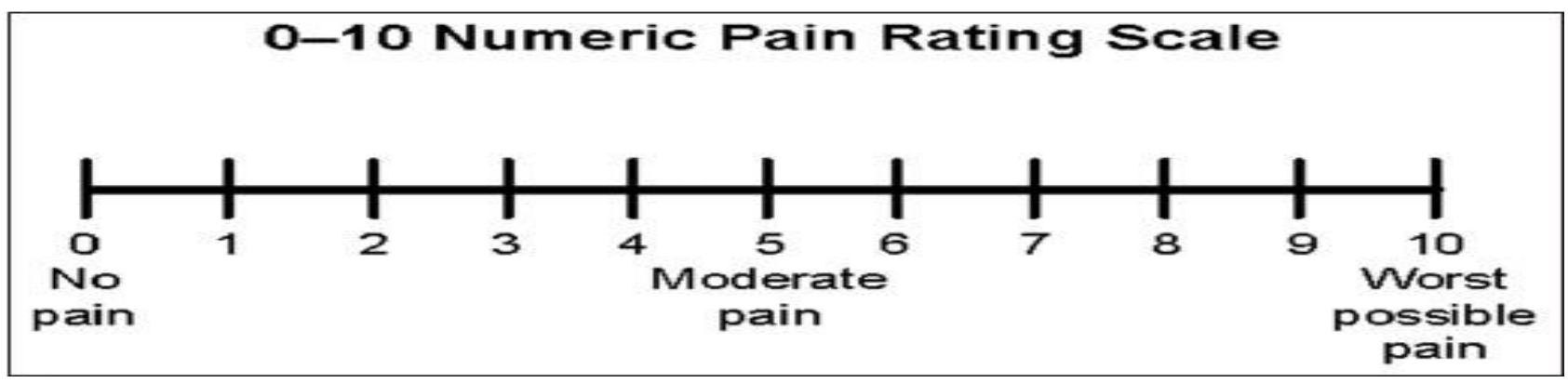

Are you experiencing any nausea? Y/N

If yes, how would you rate your nausea?
Moderate nausea
Severe nausea
Vomiting

Do you feel faint or dizzy? Y/N

If yes, how would you rate your faintness/dizziness?

Mild dizziness $\quad$ Moderate dizziness Severe dizziness Not at all difficult Somewhat difficult Very difficult

\section{Do you feel drowsy? $\quad$ Y/N}

If yes, how difficult is it to stay awake?

Comments: 


\section{Appendix B}

Patient Satisfaction Questionnaire

Hysteroscopic Surgery in a Procedure Room Compared to the Operating Room

Interviewer:

Name:

Date: $(\mathrm{mm} / \mathrm{dd} / \mathrm{yy})$

Time:

$\mathrm{AM} / \mathrm{PM}$

Before the procedure, did you feel?

$\square$ Fairly calm $\square$ A bit worried $\square$ Very worried

To what degree were you bothered by the pre-op dietary restrictions?

$\square$ Not at all $\quad \square$ Somewhat $\quad \square$ A lot

Do you feel that the verbal explanation you got from the staff before the procedure was?

$\square$ Very helpful $\square$ Fairly helpful $\square$ Not helpful

During the procedure, did you feel?

$\square$ No pain $\square$ Very little pain $\square$ Some pain $\square$ Very bad pain

Would you say that you were treated kindly and with respect during your stay?

$\square$ Strongly $\square$ Disagree $\quad \square$ Agree $\square$ Strongly disagree agree

Do you feel that the verbal instructions you were given by the staff when you were discharged (went home) were:

$\square$ Very helpful $\square$ Fairly helpful $\square$ Not helpful

Compared to how you expected it to be, was the procedure:

$\square$ Worse than expected $\square$ As expected $\square$ Better than expected

If you needed to have this procedure again, would you:

$\square$ Agree to have it done $\square$ Have it done with conscious sedation the same way (put to sleep) $\square$ Have it done without conscious sedation (fully awake)

How likely would you be to recommend this same procedure to others?

$\square$ Not at all likely $\square$ Not likely $\square$ Somewhat likely $\square$ Very likely

Did you miss any work due to your procedure?

$\square$ Yes $\square$ No

If yes, how much work did you miss?

Have you been able to return to regular activities? (i.e. laundry, cooking, chores)

$\square$ Yes $\square$ No

If yes, how long after the procedure (were you able to return to regular activities)? 
How soon after your procedure were you able to drive a car?

$\square$ Haven’t driven $\quad \square 24$ hrs after $\quad \square 72$ hrs after $\quad \square$ Immediately $\quad \square 48$ hrs after $\quad \square$ N/A

Do you have any current discomforts related to your procedure?

$\square$ Yes $\square$ No

What was the worst thing about your procedure?

What was the best thing about our procedure?

\section{Ask patients from SurgiCentre:}

Given the option to have your procedure done in a clinic where you would have only local anaesthetic, minimal dietary restrictions, very short length of time spent in hospital, and were able to drive and return to work on the same day, would you choose to have the procedure done the same way or as I just described? Why?

\section{Ask patients from MWC:}

Given the option to have your procedure done in an OR where you would have general anaesthetic (put to sleep) and spend a greater amount of time in hospital, involving more dietary restrictions and waiting longer before you could drive or return to work, would you choose to have the procedure done the same way or as I just described? Why?

\section{Additional comments:}

